\title{
Study on Consultative Agricultural Knowledge Service System
}

\author{
Wang Xiguang \\ Agricultural information institute of CAAS, Beijing 100081, China \\ wangxiguang@hotmail.com
}

\begin{abstract}
Agricultural informatization has entered a rapid development period. With the improvement of basic rural information infrastructure and the Agricultural informatization resource increase, the information service models also need reform and innovation. The Consultative knowledge service system is people-oriented and support the user interactive information exchange, and it can also provide the remote technical consultation, Remote diagnosis and the final solution for the farmers. In this paper, we used open-source system OpenMeetings to design and secondary develop, and realize remote video communication among agricultural users, agricultural Technicians and agricultural professors. This system has been integrated in China Agricultural Technology Extension informatization platform, and support serving agriculture, rural areas and peasant and agricultural informatization. The actual test result shows that the system has effectively promoted Agricultural Technology Extension and information resources integration.
\end{abstract}

Keywords: Agricultural Technical knowledge service, Remote diagnosis, OpenMeetings, Agricultural Informatization.

\section{Introduction}

In recent years, the research on knowledge service has flourished in China and abroad, but the knowledge service does not have much progress in the agricultural industry. China is a large agricultural country, and to accelerate the popularization and promotion of modern agricultural technology is one of the key solutions to solve food security [1, 2]. Entering 21st century, the transformation of information technology in China's agriculture came into a stage of rapid development. The No. 1 Documents of the central government of China continued to focus on rural areas, agriculture and farmers for many years. With the explosive growth of agricultural information from the Internet and digital environment, the problem of how to enrich and extent the agricultural technicians knowledge and thereby enhancing the contribution of science and technology in China's agriculture and increasing farmers' income has become a significant part of the three dimensional rural issues. In order to improve the traditional agricultural technology extension methods, elevating the level of grassroots agricultural technology services, the state government attaches great importance to the reform and construction of the grassroots agricultural technology 
extension system. The No. 1 Document of the central government in 2012 clearly stated that we should make full use of modern information technology and innovate the management and tools of grassroots agricultural technology extension. In order to focus on the farmers and effectively solve the various problems during agricultural production, to provide targeted agricultural technology consulting services, and to improve the quality of agricultural technology extension services, the new model of agricultural information technology is indispensable[3,4]. The knowledge service model of expert consultation establishes the interaction between agricultural experts, agricultural technicians, and farmers. Based on the online / offline communication, the one-on-one personalized consulting service can effectively narrow the distance between experts and grassroots farmers and agricultural technicians [5]. It can directly address the practical problems that occur in the production and provide corresponding solutions.

Remote video conference system originated from 1990s, gradually spreading nationwide since 2000. It is generally realized by audio/video compression and multimedia communication technology, supporting remote real-time information exchange and sharing as well as remote collaborate. Internet is utilized to satisfy geographically dispersed people's demand for audio and video communication in different regions. Currently it is mainly applied in international conference and remote teaching etc. Domestic farmers have the feature of wide geographical distribution, large user base and low computer skill. If hardware/software video conference systems are massively adopted, many arrangement and cost problems would occur. However, video conference system based on $\mathrm{B} / \mathrm{S}$ framework is widely applied since it has low cost and easy deployment and usage.

At present there are many video conference systems based on Web browsers, of which OpenMeetings is a popular open-source video conference system with abundant features and multiple language packages. It is widely applied in many fields, e.g. Ma Guodong[6] (2011) proposed to engage reference service via video conference in library combining actual business of the library. As a result, favorable effect has been achieved through application of such system. Statistics shows that 97\% townships and 80\% administrative villages have basic Internet access in 2011. Such good network basic environment offers convenient conditions for expert consultation of knowledge service system designed for large number of peasants. In this case, the system is fully operational, laying solid foundation for agricultural development and scientific benefits of farmers. In this paper, based on sufficient research of OpenMeetings, design and secondary development are carried out, and all functions of agricultural expert consultation of knowledge service system have been released. Furthermore, through observation and actual test results, the feasibility of constructing consulting knowledge service system using OpenMeetings is confirmed. 


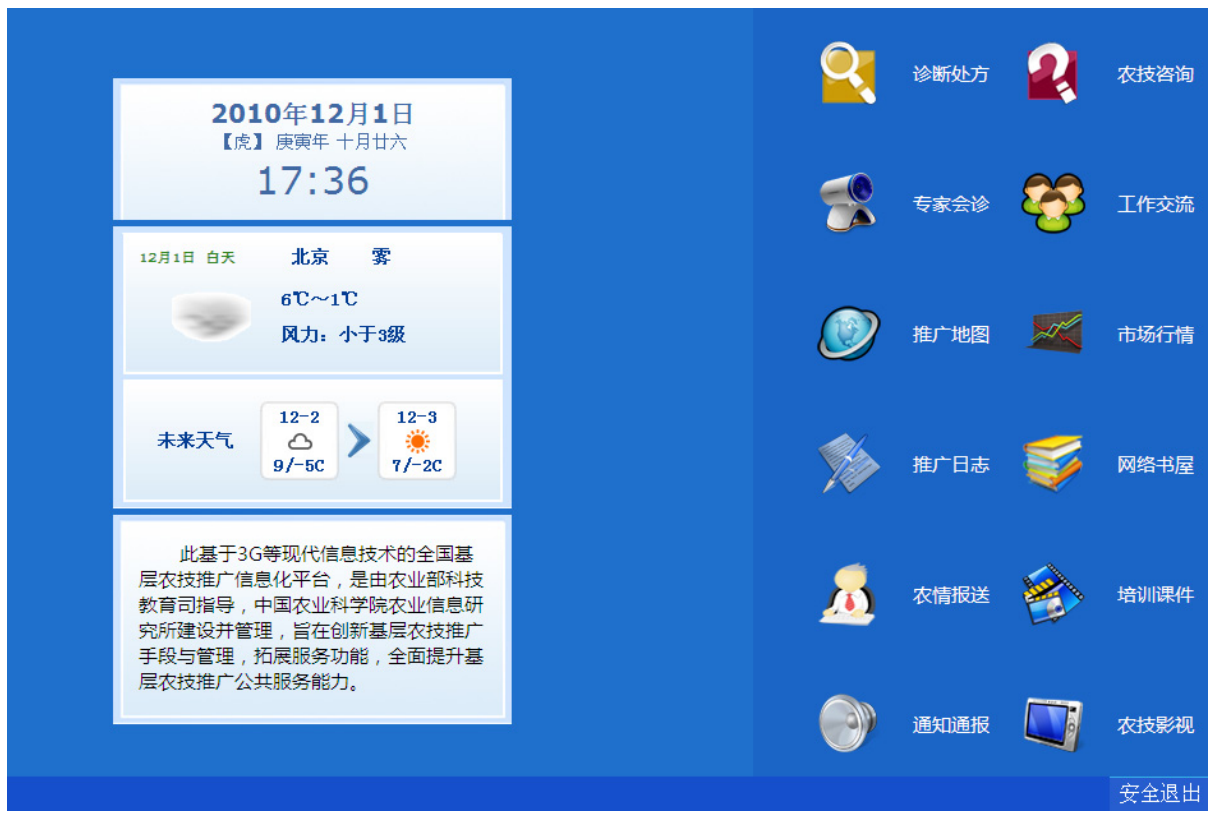

Fig. 1. China Agricultural Technology Extension informatization platform

\section{OpenMeetings Introduction}

As an open-source remote video conference system based on B/S framework, OpenMeetings can use current Internet access and limited hardware resources (PC, webcam, and microphone) to provide remote video, voice call, teaching board, realtime sharing and reading of documentary resources, instant message, interactive operation and etc. In this case, farmers' hardware requirements for video conference will be sharply reduced, simplifying users' operation. Furthermore, OpenMeetings' requirement for network bandwidth is also low, while user video default setting is 30 FPS with a video window of $320 * 240$, which only requires an upstream bandwidth of about 50KB for user with stable network. Most ADSL network nationwide could satisfy OpenMeetings' need to maintain appropriate video call with other user. There are no limitations on usage and number of users [7].

Thus, compared to the hard wired video conference, OpenMeetings has more advantages in functionality, speed, network adaptability, usability and cost. Though OpenMeetings is not as good as video conference in respect of performance and image clarity, it can be deeply integrate with other network applications. 
Table 1. OpenMeetings compare with Hardware video conference

\begin{tabular}{ccc}
\hline & OpenMeetings & Hardware video Conference \\
\hline Core Technique & $\begin{array}{c}\text { streaming media } \\
\text { service Red5 }\end{array}$ & Hardware solution \\
\hline Function & $\begin{array}{c}\text { Text Message, } \\
\text { Files Share, White } \\
\text { broad, Video Record } \\
\text { and others }\end{array}$ & $\begin{array}{c}\text { Similar With OpenMeetings, } \\
\text { variety for different bands }\end{array}$ \\
\hline Speed & $\begin{array}{c}\text { Fast after } \\
\text { optimization }\end{array}$ & Normal \\
\hline Deploy, & simply & complicated \\
\hline $\begin{array}{c}\text { Hardware } \\
\text { Requirement }\end{array}$ & PC、 Camera, & Customized video Server, Client \\
Cost & Microphone & application for PC \\
\hline Period & Low & Medium \\
\hline Network & Any & Customized Network \\
applicability & &
\end{tabular}

\section{Consultative Knowledge Service System Design}

Consultative knowledge service system, a key part of the information platform for grassroots agricultural extension, primarily provides remote expert consultative services to farmers and agricultural workers throughout the country, aimed to establish timely, accuracy and effective agriculture technology knowledge service. Through the expert consultative service system, face-to-face communication between the terminal user and experts is implemented and provide the direct and visualized remote agriculture consultative knowledge services.

The system compose with three modules real-time remote technical consulting services, remote diagnosis services for animal and plant pests and remote agricultural technology classroom. Real-time remote technical consulting service offers real-time technical answering services and technical advice for farmers, enabling experts and farmers communicate face-to-face on the Internet [8]. Remote-diagnosis services for animal and plant pests refer to an expert learning the symptom and diagnosing in the consultation room, through direct pictures, audio and video information captured by farmers in production fields with their $3 \mathrm{G}$ mobile terminals. Remote agricultural technology classroom enables the agricultural experts to start agricultural science and technology classes at any places with Internet access. The implementation process of consultative service system studied in this paper is as follows: 


\subsection{User Interface Reformation}

User interface redesign is to realize by lzx script and second develop based on the OpenMeetings. In order to make the operation more convenient, some of the widgets move to the toolbar on the left. Some frequent used buttons are put on the top, such as white board, application, document upload, video record and screen sharing. Compared with default OpenMeetings interface, the video conference panel replaces the attribute panel, the reformatted interface as the Figure 2:

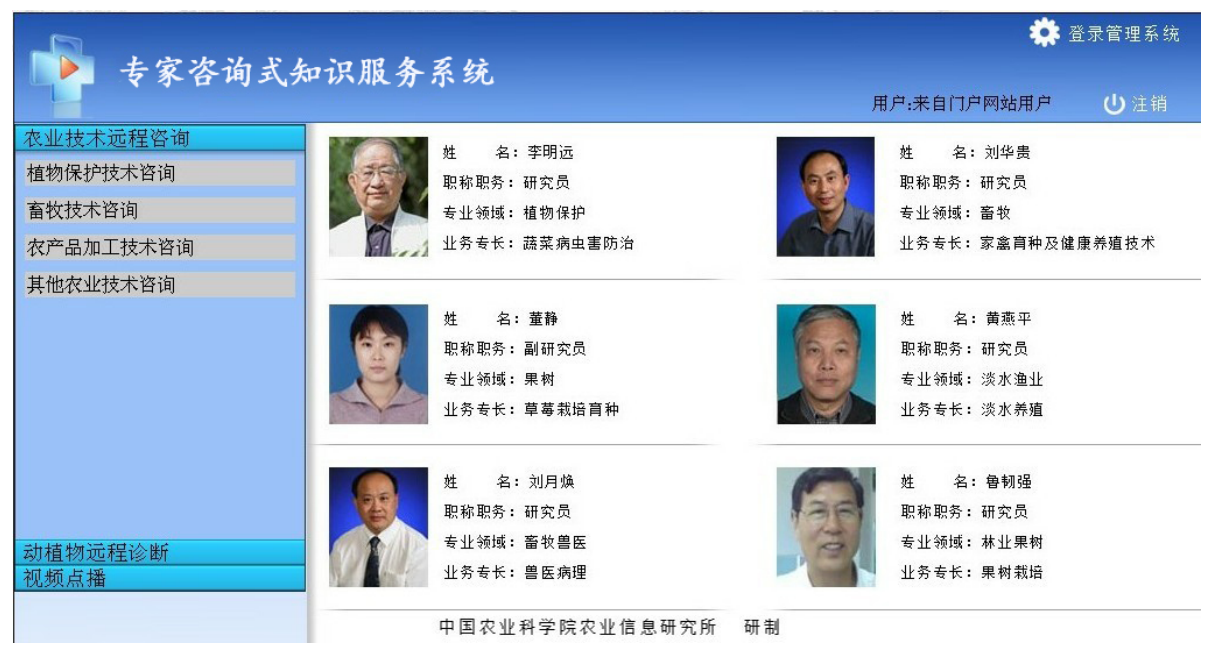

Fig. 2. Consultative knowledge service system User Interface

\subsection{SSO (Single Sign On)}

OpenMeetings executes 2 major steps to realize the SSO. First OpenMeetings use its integrated service to acquire SessionKey, and then generate a Hash string according the SessionKey to get the video conference room entrance URL address, which is similar with the external invitation URL. Meanwhile, the conference room type will be confirmed and Session will be initialed, and navigation menu resource will be released $[9,10]$.

\subsection{Calendar Management}

Administrators have the privilege to manage the calendar and assign the timesheet. The professor can provide the Consultative knowledge service and remote diagnosis services after his successful authentication. Then he can also invite some farmers or agricultural technicians to join the conference and start their face-to-face communication. Meanwhile the farmers or agricultural technicians consults the professors or ask him to on-line examine their production. If all participators sign-out and conference room is vacant, the conference session will be destroyed automatically by the system. 
Farmer can check the calendar details by clicking the calendar link after he enters the conference room. The calendar displays corresponding professor's name and their timesheet for one week. The detail information includes sequence Number, professors' name, professors' description (specialty, resume and etc.) and timesheet period.

\subsection{Video Conference Invitation}

The invitation must be send out by the conference room builder, and the invited user must have been the authenticated. The users can invite the same professor at the same time, and the professor can accept more than one invitation. You can search your target users by name location and other parameter. The Process as the following:

\subsubsection{Send out the Invitation}

According to the users' parameter (Such as invitation user ID, the authenticated user ID, video conference room ID and etc.) generate an invitation record in the Database, and set the label as 1 (1 means has been invited).

\subsubsection{Query and Process the Invitation}

If the user has been authenticated, the system will scan the database to check the invitation record. If the record is found, the user will be listed in the online user list which is located in the left side of the video conference interface.

\subsubsection{Accept or Deny the Invitation}

If the video conference room status is 1 , the dialog will be pop up to ask the user to accept the invitation. If the user has been invited in the system and accepted the invitation, he will not be invitation again. While the users accept the invitation, he can enter the conference room directly and start the video communication [10].

\subsection{Algorithms Optimization}

For the agricultural users often use the low bandwidth connection to access our knowledge service system, we must consider such situation and try to obtain highquality video communication. To enhance video communication representation in lowbandwidth network environment, 3 major solutions has been applied in the system, video frame reduction, compressed transmission, and bicubic interpolation algorithm.

\subsubsection{Frame Rate Reduction}

To ensure sound effects in video connections, our system will reduce 30 fps to $10 \mathrm{fps}$ or $5 \mathrm{fps}$, while the client using low bandwidth connection. Coupled with the compression and transmission algorithm, the real-time traffic produced by video calls can decrease from about $100 \mathrm{~KB}$ to about $20 \mathrm{~KB}$.

\subsubsection{Compression and Transmission}

With low bandwidth Internet connection, H.264 is the most efficient in video and voice coding and decoding, but it significantly raises requirements for the processing capacity of CPU. Through overall pre-research and testing, this platform finally 
adopts H.264 coding at low bandwidth and H.263 coding at high bandwidth, which is much flexible and provide better user experience.

\subsubsection{Application of Bicubic Interpolation Algorithm}

In order to reduce video transmission traffic and cope with the packets drop, Bicubic interpolation algorithm has been integrated. However, it takes in consideration of not only impact of gray value of directly adjacent point on the sampling point, but also impact from rate of gray value change between adjacent points. Thus, the bicubic interpolation algorithm can provide more accurate gray value of sampling points to be measured, with the disadvantage of large, complex and slow computation.

\section{$4 \quad$ Test Result and Analysis}

So far, expert consulting knowledge service system has implemented for half a year and has severed more than 1110 times for actual uses. In order to verify the application effect and enhance our system, appraisal system will be active at the end of video call each time, recording the call quality feedback of each time. The total effective appraisal we have received amounted to 286 times, of which positive feedback rate is more than $90 \%$. Other knowledge service system is most based on library management system or some Management Information System. All of them are lack of information exchange and user interaction and cannot provide effective and accurate solutions. This system resolves such issues in an economic and practical way. The continuous strength of communication and interaction between agricultural members, farmers and agricultural specialists make it possible for specialists to provide face-to-face onsite training and service of solving problems step by step for agricultural members through distance video function. As a result, agricultural members unnecessary to speed large quantity of time on unfamiliar question but still not solving it, nor do they need to work hurry for fear of missing the suited weather for agricultural production. Through this way, level of serves of agricultural technology will be largely enhanced, making farmers satisfied truly on site. While providing consulting service, full play of guidance in agricultural fields is given to specialists to guide agricultural members and to cultivate their abilities of solving problems. Besides, functions such as work communication, knowledge sharing, independent learning and business service are also provided for the purpose of promoting agricultural members' active participation, self-directed learning and independent creation, making agricultural members learn from each other and progress together during the process of communication with specialists and other agricultural members[11]. In addition to this, the system also makes it possible for agricultural specialists to learn about the problems faced by farmers timely and to get the key point and development direction of agricultural scientific research, enabling specialists to work on significant issues of agricultural production and rural development and hot issues concerned by farmers.

Moreover, owing to the inconsistency of internet development across the country and high geographical heterogeneity, high-speed channel and low-speed channel are installed to ensure that users with different network speed can all obtain good voice 
quality and technical service. To testify the conversation delay and fluency in a multiuser environment, tests are conducted under the condition of concurrent users of 5 , 10, 20 and 50 respectively. The specific data of test as in Table 2, the tested system is Ali Cloud Server Standard C and bandwidth is 10Mbps.

Table 2. Consultative knowledge service system test result for different Current Users

\begin{tabular}{ccccc}
\hline $\begin{array}{c}\text { Current } \\
\text { Users }\end{array}$ & $\begin{array}{c}\text { Bandwidth } \\
\text { for per- } \\
\text { user(KB/s) }\end{array}$ & $\begin{array}{c}\text { Server } \\
\text { CPU Usage }\end{array}$ & $\begin{array}{l}\text { Network } \\
\text { Delay }\end{array}$ & Fluency \\
\hline 5 Users & 85 & $34 \%$ & $\begin{array}{c}\text { Less than } \\
0.1 \mathrm{~s} \\
\text { Less than } \\
0.1 \mathrm{~s}\end{array}$ & Good \\
10 Users & 105 & $36 \%$ & $\begin{array}{c}\text { Less than } \\
0.1 \mathrm{~s}\end{array}$ & Good \\
20 Users & 129 & $40 \%$ & $\begin{array}{c}\text { Less than } \\
0.8 \mathrm{~s}\end{array}$ & Good \\
\hline 50 Users & 152 & $45 \%$ & &
\end{tabular}

From the actual test result, CPU usage is much less than $50 \%$ when the current user is added to 50, we can see that the system does not rely on the CPU and consume much CPU resources. On the other hand, the server bandwidth increases with the current user number. During the test, it increases from $85 \mathrm{~kb} / \mathrm{s}$ ( 5 current users) to 152 $\mathrm{kb} / \mathrm{s}$ (50 current users), Due to user exchange information and some control package. Limited by the test server bandwidth limitation, we did not execute the test cases for more than 50 current users. To solve such issues, we consider using the more servers and setup load balancing cluster.

\section{Conclusions}

Starting from the introduction of OpenMeetings' functions, this paper presents the basic structure and features of this system, all functions of consultative knowledgebased service system have been realized through applying the secondary development and integration of this system to basic agricultural technology extension information platform. The relatively low-cost development and deployment of this system make it possible for a full use of current network resource to shorten communication distance, which provides to agricultural production a direct, vivid and visual long-distance expertise. Consultative knowledge-based service system supports all kinds of platform and is available to most of browsers; it's so easy and simple that it effectively meets the need of long-distance consultation service. The test result of actual network operation has proved that OpenMeetings video conference system has a fine adaptability to current network in our country, even working in relatively slow networking bandwidth. In addition, basic network environment in rural area also offers a convenient condition for the coverage of expert consultative and 
knowledge-based service system to rural residents in our country, and in this way, it helps to give full play to the function of the system, which in turn lays a foundation for rural residents' obtaining of the achievement and development of agriculture. Though current system still has its flaws, for instance, large occupancy of server resource while recording a video, disconnection when the amount of users is oversized, but these problems will be studied and solved later in work.

Acknowledgment. Funds for this research was provided by the National Science and Technology Support Program(2011BAD21B01), that is Key Technologies for Agricultural Field Information Comprehensive Sensing and Rural extension.

\section{References}

1. Wu, Z.: Study on the New Knowledge Service System of Agricultural Science and Technology Based on the Farmers. Chinese Academy of Agricultural Sciences (2012)

2. Tan, C.-P., et al.: Research of Origin and Development of Agriculture Knowledge Service in China. Journal of Anhui Agricultural Sciences 12, 7440-7441 (2011)

3. Liu, J.: Thinking about innovation in the construction of agricultural knowledge service system. Agric. Network Inform. 10, 4-6 (2008)

4. Lu, Q.C., Li, Y.: Research on promotion process of knowledge service in the development of informatization in rural region of China. Technoecon. Manage. Res. 2, 92-95 (2009)

5. Zhou, G.-M., Qiu, Y., et al.: Design and Realization of Agriculture Knowledge Service System Based on Internet. Journal of Library and Information Sciences in Agriculture 02, 238-240 (2005)

6. Ma, G.: Applications of the Video-Conference Based on Open Meetings in Library. Journal of Modern Information 01, 146-149 (2011)

7. Open Meetings Home Page (May 10, 2013), http: / / openmeetings . apache.org/

8. Li, J., Wang, J., Wu, W., et al.: Design and Implementation of Web Video Conferencing System Based on Red5. Radio Communications Technology 06, 56-58+76 (2012)

9. Peng, L., Zhao, R.: The Research of Video Conference System on OpenMeetings. Computer Knowledge and Technology 12, 2909-2911+2922 (2011)

10. Lu, M., Wang, X.-D.: Design of Video Conference System Based on Techniques of FLV Streaming Media. Journal of Jilin University (Information Science Edition) 02, 186-190 (2010)

11. Tong, Y., Hu, W., et al.: A Review on the Video Quality Assessment Methods. Journal of Computer-Aided Design \& Computer Graphics 05, 735-741 (2006) 